ISSN: 2162-3104 Print/ ISSN: 2166-3750 Online

Volume 8, Issue 2 (2018), pp. 638-658

(C) Journal of International Students

http://jistudents.org/

doi: $10.5281 /$ zenodo. 1249047

\title{
"But I Learn More Bad Grammars When I Write to My Classmates": Acquiring Academic Literacies in a Multicultural Writing Class
}

Teresa Chen

California State University, Long Beach, USA

\section{ABSTRACT}

This qualitative case study sought to understand the experiences of international college students who were involved in the acquisition of academic literacies (via an English-as-a-Second-Language writing class). Data sources included observation field notes; messages posted in an online discussion forum; transcripts of interviews with five focal students and their instructor; and student-level reflective journal entries. Findings were validated via the triangulation of multiple data sources. Several themes emerged from the analyses that are associated with academic adjustment and intercultural communication, including an energetic class that highly valued participation, conflicting student views on participation, and unvalued collaboration. Implications included the provision of instructionrelated opportunities that enable students to explore the cultures and culturally diverse communication styles of their academic peers.

Keywords: Academic adjustment; Communicative language teaching; Culture; Intercultural communication

This qualitative case study sought to understand the experiences of international college students during their acquisitions of academic literacies in an undergraduate English-as-a-Second-Language (ESL) writing class. The socialization of such students into mainstream educational contexts has been a key objective of many English for Academic Purposes and ESL 
classes within English-speaking countries that host international students. These students (a) become familiar with new academic literacies, (b) obtain concepts and skills associated with success in scholarly communities, and (c) converge and learn side by side (e.g., about academic norms in host countries, cultural nuances, and how to make associated adjustments). Indeed, such students must work well with their peers in these classes in order to maximize the success of such classes. This study has examined some of the specific ways that students, with diverse backgrounds, have learned together as they have adjusted to a new academic community.

\section{LITERATURE REVIEW}

This study implemented an interpretative approach to obtain a thorough understanding of the students' experiences in natural settings as they underwent adjustments. Three lines of research informed this study: (a) communicative language teaching (CLT), (b) academic adjustment and adaptation, and (c) culture of learning. CLT is a language-teaching approach that was adopted in the class under investigation, so the first part of the review delves into two aspects of CLT that provide contextual information for the study: peer interaction and teacher roles. The second part of the review presents an overview of earlier research on the adjustments of international students. The third segment focuses on the cultures of learning that students may bring with them to host countries. While examining culture-of-learning research, the review goes beyond studies that build on or foster cultural dichotomy, which often impedes researchers from capturing the complexity of a phenomenon under study. Thus, this review collectively seeks to provide a synthesis of earlier research.

CLT focuses on the development of the communicative competencies of students via interactions in target languages (vs. masteries of language structures) (Farooq, 2015; Richards \& Rogers, 2014; Savignon, 2002b). In such student-centered and "less structurally driven" (Kern \& Warschauer, 2000, p. 5) classes, students are expected to actively participate in communicative-based tasks (e.g., negotiating meanings and constructing knowledge). These communicative tasks promote language learning and are generally collaborative. Furthermore, in pairs or small groups (vs. lecturebased classes), students have more opportunities to generate language outputs (Richards, 2006). While interacting with peers, students develop grammatical, sociolinguistic, discourse, and strategic abilities that enable 
successful communication (Canale \& Swain, 1980; Richards \& Rogers, 2014).

Peer interaction likely promotes language development (Huss, 1995) and is thus crucial in CLT classes; indeed, the advantages of peer interaction in language-learning settings are well documented (e.g., Choi, 2014; Pinter, 2007; Richards, 2006; Sato \& Ballinger, 2016). Peer interaction, via well-planned communicative tasks, enables students to experiment with target languages, offer (and receive) corrective feedback, and become more fluent via practice (Philp, Adams, \& Iwashita, 2014). Researchers have also identified factors (e.g., metacognitive instruction, student-level mutuality, and task designs) that contribute to peer interactions associated with language learning (see Philp, Adams, \& Iwashita, 2014; Sato \& Ballinger, 2016). Interestingly, the proficiency of peers is not considered a critical or determining factor; this indeed differs from the perceptions of students (that they need to communicate with native speakers, or at least with more fluent peers, in order to improve their target language). In fact, when students interact with their peers in order to complete communicative tasks, they co-create opportunities for language learning, regardless of proficiency differences. Thus, the patterns of interactions that students have co-constructed with their peers might be more significant than proficiency differences (Watanabe, 2008; Watanabe \& Swain, 2007).

When CLT classrooms have healthy levels of peer interactions teachers tend to adopt supportive (vs. leading) roles; however, the presence of teachers remains essential. Indeed, language teachers usually assume three roles (i.e., facilitator, manager, and knowledge provider); however, CLT classroom teachers mainly assume the first two roles (Gatbonton \& Segalowitz, 2005). As facilitators, they provide consultation (as needed) and support the interactions of students with other class members and a variety of learning resources. As managers, they select and assign communicative tasks, ensure that required resources are available for completing tasks, and monitor the progress of students (and keep them on track). Thus, they rarely provide direct instruction when delivering content.

Certainly, this teaching approach may not be aligned with the expectations and experiences of some international ESL students who usually need to make adjustments in order to adapt to classroom settings in light of the broader social and academic culture that they must also understand beyond just being able to put their thoughts into spoken or written words. Earlier research studies (e.g., Andrade, 2006; Andrade, 2009; 
Akanwa, 2015; Brown \& Holloway, 2008; Chen \& Yang, 2014; Kuo, 2011; Leong, 2015; Lin \& Scherz, 2014; Mesidor \& Sly, 2016; Tananuraksakul, 2012) have explored some of the academic adjustments and adaptations of international students and often noted that the prominent challenges of students are associated with language and cultural differences. In a literature review on the adjustment issues of international students, de Araujo (2011) has summarized prior studies that have consistently revealed that English proficiency is a significant factor in such adjustments.

The limited English proficiencies of ESL students have typically led to difficulties with academic adjustments (e.g., understanding lectures, participating in class, and writing research papers); however, these difficulties were not only attributable to language proficiencies but also originated from cultural differences (Abu Rabia, 2017; Alsahafi \& Shin, 2017). In new academic environments, they might not be aware of (or used to) class norms associated with communication and writing conventions, which often vary from culture to culture. In addition to rich personal and social experiences, adult learners often arrive with education-related assumptions, learning approaches, and attitudes, which generally require some modification and adjustment during the acquisition of new academic literacies.

Researchers (e.g., Akanwa, 2015; Lin \& Scherz, 2014; Mesidor \& Sly, 2016) have indicated that cultural factors (including assumptions, attitudes, expectations, and values), which manifest themselves in the disciplinary content and academic settings, contribute significantly to students' learning. Indeed, international ESL students are exposed to new academic cultures and sociocultural contexts and must hone language skills following their arrivals in English-speaking host countries. As adult learners, they come with their own approaches to learning, which may not meet the demands of the educational system in their host country. Accordingly, they often need to modify their learning strategies and go through a process of adjustment.

Culture of learning plays a significant role in the adjustment process. Culture of learning is a cultural framework that shapes students' perceptions of learning and their evaluations of the performances of class members (Cortazzi \& Jin, 2013). Previous studies (Carson \& Nelson, 1996; Ozer, 2015; Tan \& Goh, 2006) on the academic adjustment or adaptation of international students have utilized cultural dichotomies to juxtapose Western and non-Western cultures. The cultures mentioned in these studies 
usually corresponded to homogeneous ethnic traditions; the differences between cultures have often been generalized as contrasts (e.g., individualism vs. collectivism). Methodological approaches (e.g., comparative research) in these studies promote a general picture of an ethnic group at a point in time. However, such approaches have seldom considered cultural fluidity and individual differences within cultural and ethnic groups. While this line of research has provided a reference point (e.g., McIntosh, Connor, \& Gokpinar-Shelton, 2017) for the present study to obtain a preliminary understanding of the ESL participants, this study did not take a reductionist view of culture, which may unintentionally foster cultural stereotyping (Ronai \& Lammervo, 2017).

This study, which adopted a view that culture is dynamic rather than static, avoided placing participants into cultural categories. Studies about cultural issues in TESOL (Teaching English to Speakers of Other Languages) and its affiliated fields have demonstrated the confinement of traditional cultural groups. For instance, Nunan and Choi (2010) have presented an edited collection of reflective narratives, which candidly portray the constant interaction of language, culture and identity. Likewise, Atkinson and Sohn (2013) have vividly illustrated their research participant's multiple, adaptive, and emergent cultural identities. Even in the field of constrastive/intercultural rhetoric, which compares languages in different cultures, scholars have recognized the need to view discourse and culture in more dynamic manners (Belcher, 2014). These previous studies have consistently demonstrated the evolving and fluid nature of culture. With this view of culture, this study explored and interpreted the participants' experiences during their acquisition of new academic literacies in an ESL communicative class.

\section{RESEARCH METHOD}

The following was the central question guiding this study: "What were the experiences of international college students in an ESL writing class that had adopted a communicative language teaching approach?" This question led to the use of a qualitative approach, which aimed to obtain a holistic understanding of the experiences of students in a specific context. The study subsequently adopted an emergent design, which enabled the researcher to shape the research direction and foci during data collection. 


\section{Data Collection}

Data collection primarily took place in an ESL academic writing class for undergraduate students at a large U.S. public university. Undergraduate university students took an English placement test; they were required to take the class if their test results indicated a need for help with college-level writing. The class under investigation was a second course in a sequence of two. Throughout the semester, the class focused on five themes/units; research-related observation fieldwork covered a complete, three-week unit on culture shock. Interviews were subsequently conducted outside of class - after observation data were analyzed.

Table 1. Participating Students

\begin{tabular}{lcccc}
\hline Pseudonym & Gender & Native Language & $\begin{array}{c}\text { Academic } \\
\text { Level }\end{array}$ & $\begin{array}{c}\text { Residency in } \\
\text { the U.S. }\end{array}$ \\
\hline Akira & $\mathrm{M}$ & Japanese & Exchange & $<1$ year \\
Alejandro & $\mathrm{M}$ & Spanish & Exchange & $<1$ year \\
Anita & $\mathrm{F}$ & Arabic & Freshman & $<1$ year \\
Antonio & $\mathrm{M}$ & Spanish & Freshman & $<1$ year \\
Carlos & $\mathrm{M}$ & Spanish & Freshman & 3 -4 years \\
Claudia & $\mathrm{F}$ & Portuguese & Junior & $1-2$ years \\
Domingo & $\mathrm{M}$ & Spanish & Freshman & $<1$ year \\
Doug & $\mathrm{M}$ & Vietnamese & Freshman & 19 years \\
Insook & $\mathrm{F}$ & Korean & Sophomore & $4-5$ years \\
Jeeyoung & $\mathrm{F}$ & Korean & Exchange & $<1$ year \\
Jose & $\mathrm{M}$ & Spanish & Freshman & $<1$ year \\
Julio & $\mathrm{M}$ & Spanish & Exchange & $<1$ year \\
Kim & $\mathrm{F}$ & Korean & Exchange & $<1$ year \\
Mariko & $\mathrm{F}$ & Japanese & Exchange & $<1$ year \\
Nissa & $\mathrm{F}$ & Arabic & Freshman & $<1$ year \\
Sana & $\mathrm{F}$ & Arabic & Freshman & $<1$ year \\
Wakako & $\mathrm{F}$ & Japanese & Exchange & $<1$ year \\
Zara & $\mathrm{F}$ & Malay & Senior & $2-3$ years \\
\hline
\end{tabular}

Participants included the instructor and 18 students from countries around the world; indeed, eight were from Asia, two were from Egypt, one was from the Middle East, and seven were from Central or South America. Half of the students were placed into this class following the English placement test; the other half took this class after completing an associated, prerequisite course. Table 1 contains a more detailed profile of each student. 
The research protocol was approved by the institutional review board (IRB) at the university and all participants gave informed consent prior to their participation in the study.

This study involved multiple methods of data collection (e.g., class observations, online observations, semi-structured interviews, and surveys). Multiple data sources enhanced the establishment of trustworthiness, as emphasized by Lincoln and Guba (1985). Major data sources included (a) observation field notes from nine, 50-minute class sessions; (b) messages posted in an online class discussion forum; (c) transcripts of interviews with the instructor and five focal students; (d) all participating students' reflective journal entries; and (e) surveys containing the students' demographic information and attitudes toward the use of online discussions in association with this class. Other data (e.g., a course packet) were collected and examined to obtain a thorough understanding of the pedagogical context. Pseudonyms were utilized in data collection, data analysis, and report writing.

\section{Data Analyses}

At the initial stage of data analysis, several preliminary themes were revealed via open coding of observation field notes and messages submitted in the online class discussion forum. These themes helped to (a) identify key informants and (b) plan for subsequent data-collection sessions. For example, the first three field observation sessions revealed that when provided with the same learning opportunities, the 18 students behaved very differently in terms of verbal participation in class activities. Indeed, this has been demonstrated in the following excerpt from a class observation field note:

The instructor said, "Okay, back to the homework. You can raise your hand. How does the author [of an assigned reading] define culture shock?" Three students raised their hands. The instructor sounded disappointed: "The same people raised their hands. Always the same people."

Thus, it is evident from the descriptive observation field notes that a couple of students participated, verbally, in class as much as possible.

Quantitative data were collected, analyzed, and confirmed the frequency of student participation (e.g., asking and answering questions) on an individual basis - within lectures and whole-class discussions. An initial analysis of the qualitative and quantitative data indicated that the students 
could be divided into two groups: those who were (a) outspoken and (b) fairly reticent. The integration of the aforementioned finding with data from each survey (including each participant's background information) led to the discovery that the line dividing the two groups coincided almost exactly with an ethnic and cultural boundary-specifically, between the Hispanics/Egyptians and the Asians. Indeed, the Hispanic and the two Egyptian students were active speakers in class; however, all of the Asian students as a group-except the one from Vietnam who had lived in the United States for 19 years - spoke significantly less.

The preliminary data analysis confirmed the rate that participating students adjusted to class norms and expectations (e.g., via active verbal participation); indeed, this varied to a certain extent among students, indicated a need to further explore such differences (during subsequent observations and interviews), and identified (via a composite data analysis and consultations with the course instructor) two more expressive and three less expressive students to observe and interview. At this stage, it became apparent that an in-depth exploration could focus on educational and cultural differences exclusively; subsequent interview sessions could focus on how student backgrounds affect adjustments to specific teaching approaches adopted in the class. A further thematic analysis (of subsequent interview transcripts, reflective journal entries, and an attitudinal survey) contributed to the refinement of themes (e.g., cultural differences and participation in class discussions).

\section{Validation Strategies}

The findings were validated via the triangulation of the multiple data sources. An example of this triangulation involved student views of collaborative learning (e.g., peer editing). The researcher first noticed via the journal entries that students did not seem to value peer editing. Indeed, the following quote was recorded in a student journal entry and submitted to the instructor:

I wonder how helpful peer editing is. I like reading another student's work a little but I do not think it is helpful. One of the reasons is that there is another better editor, you the teacher, so I do not rely on the less reliable one.

The finding was later confirmed during a class observation session when the instructor spoke to the students about the journal entries on peer editing and 
clarified the benefit of this activity. The instructor also mentioned in her interview with the researcher, "I find a lot that students don't take the comments of their peer editor. They'll get peer editing comments and my comments back and they'll revise their work based on my comments only." Additionally, interviews between the focal students and researcher revealed the same attitude toward peer editing. A series of triangulations - such as the aforementioned example - were conducted when major and subthemes emerged and subsequently validated the findings.

In addition to triangulation, this study employed the following strategies to ensure rigor: peer debriefing, reflexivity, member checking, and thick description. While working on the data analysis, the researcher periodically consulted with two "disinterested" colleagues (Lincoln \& Guba, 1985 , p. 308) who reviewed the results of the analysis and commented on the interpretations. During debriefing sessions, the researcher could examine individual biases, test working hypotheses, and defend emergent findings. The researcher's reflective journal helped to clarify individual assumptions and perspectives, record methodological decisions (and associated rationales), and deliberate on ethical issues during the research process. Once a first draft report was completed, all five focal students and the course instructor received a copy of the report and had opportunities to comment; indeed, all of them expressed agreement with the interpretations and provided positive, supportive feedback. In order to attain transferability (i.e., external validity of qualitative research), the report provided detailed information - sometimes with relevant data excerpts - about the setting and participants, with the goal of facilitating naturalistic generalization (Stake, 1995). These four strategies helped to establish the trustworthiness of this study.

\section{FINDINGS}

The study examined the experiences of international college students as they acquired academic literacies in a CLT class and focused on their in-class interactions and collaborations. The following three major themes were subsequently identified (following the data analysis): (a) an energetic class that highly valued participation, (b) the conflicting views of talkers and nontalkers on participation, and (c) collaborations not valued by students. The following discussion initially describes class context and then presents findings with respect to each of the three themes. Please note that excerpts 
(i.e., from interview transcripts and journal entries) are shown as in the original data set (i.e., without editing) in order to maintain the fidelity of students' voices.

\section{Contextual Information about the Class}

The class in this study offered English instruction, addressed the unique academic needs of international students, and enabled students to obtain necessary academic literacies - in order to communicate in English successfully and in accordance with discourse conventions in Englishspeaking academic contexts. The class was aligned with the communicative curriculum proposed by Savignon (2002a), with (a) an emphasis on developing communicative competencies via interactions in the target language, (b) cooperative (vs. individualistic) approaches to learning, (c) the usage of authentic texts in learning situations, and (d) identifications of linkages between classroom learning and usages of the target language outside of the classroom (Butler, 2011; Nunan, 1991; Richards, 2006).

The course content advanced from the introduction and analysis of essay components to the discussion and practice of different types of expository and persuasive writing. Students also learned about basic library research and U.S. academic norms (e.g., how to acknowledge sources and avoid plagiarism). During the semester, the students wrote four essays, one five-to-seven-page research paper, and a few paragraphs and summaries; before they submitted their final drafts (for each major assignment), they had opportunities to seek feedback and revise their papers. These students generally showed improvement via these revision processes (e.g., self- and peer-editing and instructor feedback).

The class also provided opportunities for students to learn aboutand adjust to - the U.S. culture (e.g., students contemplated, via discourse and in writing, the norms in their home countries vs. those in the United States). However, the curriculum was not specifically designed to promote intercultural understandings among students (who represented different cultural and educational backgrounds). Thus, while most of the in-class activities, readings, and discussions focused on the prior overseas experiences of the students and cultural differences in the United States (vs. their home countries), the content did not focus on cultural differences among the students in this class. 


\section{Energetic Class that Highly Valued Participation}

class emphasized English-communication skills via in-class student interactions; student learning was further enhanced via computer-assisted linkages between classroom activities and the usage of English outside the classroom. The instructor, Lisa (pseudonym), liked to engage and interact with students; this promoted friendly interactions. Before and after class, she spoke with the students in a very relaxed manner, on a variety of topics (e.g., class assignments, queries on writing in English, and extracurricular activities).

During class meetings, Lisa continued to communicate with the students in a very casual way and always encouraged student participation. Indeed, she energized the class (e.g., by her lively facial expressions, animated gestures, and sonorous voice). Certainly, the class was not always interactive or engaging for all students - and the energy level could not be sustained without the participation of all students. In fact, Lisa once told the students, "The class is a lot more boring if you feel bored-if you don't participate, if there is no energy for me to go on." Fortunately, there were usually several students who contributed (and thus helped to maintain the energy levels).

\section{Talkers' and Non-talkers' Conflicting Views on Participation}

The "talkers" in class included a group of Hispanic students, two sisters from Egypt (who were educated in British schools or British-related systems), and a freshman who was born in Vietnam but moved to the United States with his family when he was two weeks old. Some of them were so active that the instructor needed to remind them that they would have to continue their side conversations "in a whisper." When these students were placed in a group with less expressive students, they played the leading roles and took the floor during discussions most of the time.

Student journal entries and interviews (with the researcher) showed that they all wanted more opportunities and time to express their ideas; however, it was interesting to note that certain realities were perceived by the expressive students and non-talkers very differently. For example, the talkers felt that "everyone opened up"; however, the non-talkers felt that "not everyone gets a chance to participate in class." Indeed, a student from Mexico was one of the most expressive students in class and was not aware that the Asian students in his group spoke infrequently (until the researcher pointed this out to him). When prompted, he looked puzzled and then came 
to this realization suddenly (as indicated in the following interview excerpt): "They don't? They don't? Ah, yeah, they don't speak often." Similarly, a student from Egypt did not perceive that she was one of the talkers who frequently dominated discussions; however, she did notice that her fellow talkers (most of whom were native speakers of Spanish) took the floor most of the time. In her reflective journal to the instructor, she wrote: "...sometimes I get placed with people that keep talking and I don't want to sound me[a]n to tell them to stop talking."

Even this expressive student reported difficulty with inserting a word in edgewise. The less expressive students experienced even more difficulties with group discussions; indeed, a student stated that "the class has been too active. It makes me a little bit nervous." Another student compared the class with one she had taken previously (in an interview session):

Last semester or the semester before that I took an ESL class, too. But in that class, I didn't have any problem like that. People had equal chances to [participate]. It's not Lisa's problem. We just have a few students - some people - that speak like more than necessary.

The students evidently had different notions about how much participation was "necessary" or appropriate in group discussions.

\section{Collaboration Not Valued by Students}

The students, in general, did not value collaboration with their peers. Indeed, data indicated the following three subthemes (relevant to collaboration): (a) misunderstandings among the students that hindered their collaborations, (b) students' lack of familiarity with the educational ideas and practices in class, and (c) students' preoccupations with accuracy (which was preventing them from working effectively with their fellow students). In the CLT class, the instructor assigned many collaborative or cooperative communicative tasks. From time to time, the students were given directions to participate in prewriting brainstorming activities in small groups and to talk about (or comment on) one another's writing drafts. When students brought their own communication styles (and expected others to communicate as they did), they did not think that they worked productively with their peers.

Most non-talkers came from Asian countries where it is regarded as impolite to put a word in others' narrations or conversations. However, most of the talkers were Hispanic or had traveled widely; thus, interrupting a 
conversation was familiar to them. Oftentimes, the students did not realize the differences; thus, their communications frequently ended in misunderstandings (as illustrated in the following interview excerpt):

Maybe I shouldn't have this feeling but in the first time I found a little bit I didn't like some of them in my class.... Some of them like, they really speak it out what they have in mind. Yeah, I know that's a good thing. You know, you're supposed to talk like often, but sometimes even in the small group discussion some of them like, really, bothering other people. They are acting like teachers, you know. Other people like getting little chance of speaking.

Classroom observations also yielded several examples of more expressive students enthusiastically trying to offer "help"; in these instances, the students who were usually reticent took a step even further back. Unfortunately, the students who thought they were benevolently offering assistance never realized that their efforts were not appreciated - and indeed were regarded as intimidating (and going too far).

In addition, some students did not seem to know how to proceed with group work, as illustrated by a student from Korea: "Sometimes we don't have things to talk about. For example, if we are doing some exercises, we do the exercise in a group. We just sit together and do it by ourselves [individually]." He also mentioned: "When you're working in groups, you want the whole group, all the group members to do in an organized way, to do it your way.... I don't like to work in a group. I'd rather do it by myself." Another student commented on her experience working with peers in the class: "I don't care about other classmates. I don't think it [interacting with the other students] is important in this class." These students were obviously not familiar with the process (or the value) of collaborative activities.

Furthermore, the students' preoccupations with accuracy often hindered their abilities to collaborate. Indeed, one female student had immigrated from Korea, attended high school in the United States, spoke English fluently, and wrote relatively well (according to the instructor); however, she explained why she tended not to interact much with two female students from Egypt (who were two of the most expressive students in class): "I couldn't speak like that perfect.... They were like, you know, the Americans. They speak perfect." The students' preoccupation with 
accuracy was also reflected in their online discussions. This type of preoccupation made their compositions (for the online posts) timeconsuming; indeed, they contributed to the class online forum minimally and only to fulfill the minimal class requirement. A student even said that writing took him a great deal of time; thus, he barely contributed beyond the requirements. Another student acknowledged that she did not contribute as often as she would have liked and expressed her disappointment with herself in a journal entry to the instructor: "I know that each paper does not take long time as you told me! But, I cannot do my best for each homework! Every time I felt bad because I couldn't do my best." Evidently, these students' quests for perfection did not benefit in-class or online collaborations.

The data obtained from observations, student journal entries, and interviews with the focal students all showed that the students did not see the rationale for (or the benefit of) interacting with their fellow students (who were also working on developing academic literacies). A student even mentioned in an interview that she preferred writing to native English speakers (e.g., the instructor) because she would "learn more bad grammars" when communicating with non-native speakers. Indeed, this student not only set high standards for herself but she also expected perfection from her interlocutors.

\section{DISCUSSION}

These three major themes (presented above) highlight the experiences of participating students in the CLT class. While talkers and non-talkers had different views on their abilities to participate in discussions, they both agreed that the class was highly interactive. The confidence of the talkersin their own English skills, the conversation styles that they had adopted, and their familiarity with U.S. classroom culture (which emphasizes active student participation) - made them more willing and able to participate verbally (vs. their less expressive counterparts). Most of the less expressive students came from Japan and Korea, where teachers are usually regarded as the most knowledgeable people in classrooms and thus the most reliable sources of information.

When the students came to this dynamic and communicative classroom, they found that their prior strategies for academic success did not work in this class. Indeed, some of them also started to realize that many of their 
prior class norms did not fit into this new learning environment. For example, active verbal participation (which had been discouraged by instructors and regarded as "showing off" by peers in their home countries) was valued in this class; indeed, "silence is golden" was no longer true here. Hardworking and silent students - who were regarded as "teachers' dreams" in their home countries - were now viewed as "non-participants" (and thus negatively) in this class.

In addition to different class norms, the students followed different communication styles, which varied from culture to culture (Alfaraz, 2009). While they adhered to their own norms correspondingly, they evidently had different notions about how much participation in group discussions was "necessary" or appropriate. They also did not realize that they used conversation strategies (e.g., turn-taking, back-channeling, and repairing) in different ways than their fellow students. Also, when the students participated in group discussions with their multicultural counterparts, the talkers did not pay special attention to sharing the floor; furthermore, nontalkers (even talkers sometimes) did not know how to gain the floor. Indeed, the data in this study showed that the differences in communication styles (turn-taking styles in particular, including the quantities of overlap or simultaneous talk accepted by each student) contributed to misunderstandings among students and were on a par with the findings obtained by Berry (1994) on turn-taking. Such misunderstandings consequently led to the students' not-so-positive attitudes toward working together-and to less communication amongst themselves.

Over time, studies have noted that when students participate less frequently in class discussions, they have often arrived from Asian countries where cultural expectations for high academic achievement have tended to promote (a) perfectionism (Hamamura \& Laird, 2014; Nilsson, Butler, Shouse, \& Joshi, 2008) and (b) communication apprehension (Matsuoka, 2008). These students have often been cautious and usually organized ideas well in their minds before speaking out; thus, they have not been able to catch speech flow. Indeed, by the time they have been ready to talk about a certain topic, many of their fellow students have already moved onto another one. In this highly interactive, present-day class, slower talkers especially had more difficulty with joining in an ongoing conversation.

The students did follow instructions, make adjustments along the way, and manage to complete the assigned tasks for the class on time, despite their limited knowledge of U.S. class norms, different 
communication styles - and concerns over making mistakes (which have encumbered their group work). Certainly, it was evident that many explicit and implicit norms upheld by the students (as well as their educational beliefs) had significant effects on their adjustments in class. When these old and new educational practices were in conflict, the students were most likely striving to follow new class norms - even though they faced challenges emotionally. For example, they would reluctantly work with peers in their own ways and tried their best to engage in discussions to meet class requirements and expectations. However, when students lack familiarity with some of the key educational ideas (e.g., social learning), they might feel less appreciative of certain assigned tasks (e.g., group discussions and peer-editing). Indeed, they might attempt to - or even force themselves tojoin the collaborative activities just to fulfill class demands; however, their work together might not be as fruitful as it could have been.

\section{CONCLUSION AND IMPLICATIONS}

While this study is based on prior studies on cultural differences, it did not embark on a "dichotomous classification" (Shiau, 2015, p. 44) to assign participants into cultural groups. Instead, it adopted an interpretative approach to study the students' experiences in a natural setting (as their stories unfolded and emerged). This study demonstrated that the participants and context under investigation were dynamic and multidimensional. Moreover, there has been little empirical research that explores student challenges associated with interacting with fellow multicultural students (who bring diverse past experiences, backgrounds, and add more variables to such contexts). Thus, this study adds new knowledge to this field of research - via its focus on the interactions of students with culturally diverse peers in a holistic context - and holds the following pedagogical implications.

International students need to have opportunities to learn about the backgrounds and cultures of their fellow students, in addition to comparing cultural differences between the host country and their respective home countries. As mentioned earlier, students in this class learned about the U.S. culture via class activities and assignments that aimed to acclimate them to U.S. academic environments. However, while differences between the host and home countries were highlighted (and indeed became salient to the students), the students disregarded or overlooked the diverse backgrounds of 
their classmates (with whom they interacted often). Knowledge about the host culture is certainly a must; however, multicultural awareness is also critical to the education of international students in culturally diverse classes like the one under investigation. Instructors should take further steps to promote intercultural understanding among class members and raise the awareness of students by updating the design of their courses (the readings and discussions, activities and assignments, assessment and teaching strategies).

Students in a culturally heterogeneous class have a variety of culture-specific communication styles and value systems and it is crucial for educators to appreciate student diversity and facilitate the construction of a learning environment that acknowledges different communication styles. In order to minimize misunderstandings among students from different backgrounds, it is important to explicitly make them aware of the different styles employed by themselves and their peers. Indeed, it is also recommended that students be given training in interaction strategies (e.g., via listening skills, maintaining their turns, and learning how to interrupt conversations politely), so that they will be able to interact more effectively and comfortably in a multicultural setting.

Instructors also need to clarify the rationale for adopting such a teaching approach to encourage interactions and collaborations among students who may feel that it is not beneficial to communicate and learn with their non-native, English-speaking peers. The provision of evidence that shows the effectiveness of this approach may lead to the understanding and eventual acceptance of this approach by students. Students likewise need to be convinced that, in addition to their native-speaking instructor, they and their fellow students have much to offer to their language learning, as indicated by previous research on peer interaction (e.g., Watanabe, 2008; Watanabe \& Swain, 2007). Indeed, the students will be less inclined to bestow the class authority solely upon the instructor and will feel empowered to co-construct opportunities for communication with their fellow students with such an understanding.

Lastly, ESL instructors are usually on the frontline working with (and supporting) international students. They tend to have a higher level of intercultural sensitivity (vs. students and non-ESL instructors) due to their professional training and experiences (Nieto \& Booth, 2010). Thus, it would be ideal if ESL instructors could equip their students with the same sensitivity that they themselves have and, together with the students, create 
classroom settings with all members-acknowledging different communication styles, promoting intercultural understandings, and discussing the benefits of the teaching and learning approaches employed in class. Such learning environments will surely help to ease adjustmentrelated student difficulties associated with acquisitions of academic literacies.

\section{REFERENCES}

Abu Rabia, H. M. (2017). Undergraduate Arab international students' adjustment to U.S. universities. International Journal of Higher Education, 6(1), 131139. doi:10.5430/ijhe.v6n1p131

Alfaraz, G. G. (2009). Conversing through overlaps: Information status and simultaneous talk in Cuban Spanish. Multilingua, 28, 25-44. https://doi.org/10.1515/mult.2009.002

Alsahafi, N., \& Shin, S. (2017). Factors affecting the academic and cultural adjustment of Saudi international students in Australian universities. Journal of International Students, 7(1), 53-72.

Andrade, M. S. (2006). International students in English-speaking universities: Adjustment factors. Journal of Research in International Education, 5(2), 131-154. doi:10.1177/1475240906065589

Andrade, M. S. (2009). The effects of English language proficiency on adjustment to university life. International Multilingual Research Journal, 3, 16-13. doi:10.1080/19313150802668249

Akanwa, E. E. (2015). International students in western developed countries: History, challenges, and prospects. Journal of International Students, 5(3), 271-284.

Atkinson, D., \& Sohn, J. (2013). Culture from the bottom up. TESOL Quarterly, 47, 669-693. https://doi.org/10.1002/tesq.104

Belcher, D. (2014). What we need and don't need intercultural rhetoric for: A retrospective and prospective look at an evolving research area. Journal of Second Language Writing, 25, 59-67. https://doi.org/10.1016/ j.jslw.2014.06.003

Berry, A. (1994). Spanish and American turn-taking styles: A comparative study. Pragmatic and Language Learning: Monograph Series, 5, 180-190.

Brown, L., \& Holloway, I. (2008). The adjustment journey of international postgraduate students at an English university. Journal of Research in International Education, 7(2), 232-249. doi:10.1177/1475240908091306

Butler, Y. G. (2011). The implementation of communicative and task-based language teaching in the Asia-Pacific region. Annual Review of Applied Linguistics, 31, 36-57. https://doi.org/10.1017/S0267190511000122 
Canale, M., \& Swain, M. (1980). Theoretical bases of communicative approaches to second language teaching and testing. Applied Linguistics, 1(1), 1-47.

Carson, J. G., \& Nelson, G. L. (1996). Chinese students' perceptions of ESL peer response group interaction. Journal of Second Language Writing, 5(1), 119.

Chen, D., \& Yang, X. (2014). Striving and thriving in a foreign culture: A mixed method approach on adult international students' experience in U.S.A. Journal of Education and Training Studies, 2(3), 18-25. doi:10.11114/jets.v2i3.353

Choi, J. (2014). Online peer discourse in a writing classroom. International Journal of Teaching and Learning in Higher Education, 26(2), 217-231.

Cortazzi, M., \& Jin, L. (Eds). (2013). Researching culture of learning: International perspectives on language learning and education. New York, NY: Palgrave.

de Araujo, A. A. (2011). Adjustment issues of international students enrolled in American colleges and universities: A review of the literature. Higher Education Studies, 1(1), 2-8. doi:10.5539/hes.v1n1p2

Farroq, M. U. (2015). Creating a communicative language teaching environment for improving students' communicative competence at EFL/EAP university level. International Education Studies, 8(4), 179-191. doi:10.5539/ies.v8n4p179

Gatbonton, E., \& Segalowitz, N. (2005). Rethinking communicative language teaching: A focus on access to fluency. Canadian Modern Language Review, 61(3), 325-353. https://doi.org/10.1353/cml.2005.0016

Hamamura, T., \& Laird, P. G. (2014). The effect of perfectionism and acculturative stress on levels of depression experienced by East Asian international students. Journal of Multicultural Counseling and Development, 42, 205217. doi:10.1002/j.2161-1912.2014.00055.x

Huss, R. L. (1995). Young children becoming literate in English as a second language. TESOL Quarterly, 29(4), 767-774. doi:10.2307/3588175

Jin, L., \& Cortazzi, M. (2006). Changing practice in Chinese culture of learning. Language, Culture and Curriculum, 19(1), 5-20. http://dx.doi.org/10.1080/ 07908310608668751

Kern, R., \& Warschauer, M. (2000). Introduction: Theory and practice of networkbased language teaching. In M. Warschauer \& R. Kern (Eds.), Networkbased language teaching: Concepts and Practice (pp. 1-19). New York: CUP.

Kuo, Y. (2011). Language challenges faced by international graduate students in the United States. Journal of International Students, 1(2), 38-42.

Leong, P. (2015). Coming to America: Assessing the patterns of acculturation, friendship formation, and the academic experiences of international students at a U.S. college. Journal of International Students, 5(4), 459-474. 
Lin, S., \& Scherz, S. D. (2014). Challenges facing Asian international graduate students in the US: Pedagogical considerations in higher education. Journal of International Students, 4(1), 16-33.

Lincoln, Y. S., \& Guba, E. G. (1985). Naturalistic inquiry. Newbury Park, CA: Sage.

Matsuoka, R. (2008). Communication apprehension among Japanese college students. Journal of Pan-Pacific Association of Applied Linguistics, 12(2), $37-48$.

Mcintosh, K., Connor, U., \& Gokpinar-Shelton, E. (2017). What intercultural rhetoric can bring to EAP/ESP writing studies in an English as a lingua franca world. Journal of English for Academic Purposes, 29, 12-20. https://doi.org/10.1016/j.jeap.2017.09.001

Mesidor, J. K., \& Sly, K. F. (2016). Factors that contribute to the adjustment of international students. Journal of International Students, 6(1), 262-282.

Nieto, C., \& Booth, M. Z. (2010). Cultural competence: Its influence on the teaching and learning of international students. Journal of Studies in International Education, 14, 406-425. doi:10.1177/1028315309337929

Nilsson, J. E., Butler, J., Shouse, S., \& Joshi, C. (2008). The relationships among perfectionism, acculturation, and stress in Asian international students. Journal of College Counseling, 11, 147-158.

Nunan, D. (1991). Communicative tasks and the language curriculum. TESOL Quarterly, 25(2), 279-296.

Nunan, D., \& Choi, J. (Eds.). (2010). Language and culture: Reflective narratives and the emergence of identify. New York, NY: Routledge.

Ozer, S. (2015). Predictors of international students' psychological and sociocultural adjustment to the context of reception while studying at Aarhus University, Denmark. Scandinavian Journal of Psychology, 56(6), 717-725. doi:10.1111/sjop.12258

Philp, J., Adams, R., \& Iwashita, N. (2014). Peer interaction and second language learning. New York, NY: Taylor \& Francis.

Pinter, A. (2007). Some benefits of peer-peer interaction: 10-year-old children practicing with a communication task. Language Teaching Research, 11(2), 189-207. doi:10.1177/1362168807074604

Richards, J. C. (2006). Communicative language teaching today. Cambridge, UK: Cambridge University Press.

Richards, J. C., \& Rogers, T. S. (2014). Approaches and methods in language teaching (3rd ed.). Cambridge, UK: Cambridge University Press.

Ronai, K., \& Lammervo, T. (2017). Australian TESOL Teachers' Cultural Perceptions of Students. Journal of Language, Identity \& Education, 16(5), 313-327. https://doi.org/10.1080/15348458.2017.1350824 
Sato, M., \& Ballinger, S. (Eds.). (2016). Peer interaction and second language learning: Pedagogical potential and research agenda. Amsterdam, The Netherlands: John Benjamins.

Savignon, S. J. (2002a). Communicative curriculum design for the 21 st century. Forum, 40(1), 2-7.

Savignon, S. J. (Ed.). (2002b). Interpreting communicative language teaching: Contexts and concerns in teacher education. New Haven, CT: Yale University Press.

Shiau, H. (2015). Beyond the cultural dichotomy, what do we share?: An ethnographic study of intergenerational smartphone MMS use in sojourning experiences. Journal of Asian Pacific communication, 25(1), 42-62. doi:10.1075/japc.25.1.03shi

Stake, R. E. (1995). The art of case study research. Thousand Oaks, CA: Sage.

Tan, J. K. L., \& Goh, J. W. P. (2006). Why do they not talk?: Towards an understanding of students' cross-cultural encounters from an individualism/collectivism perspective. International Education Journal, 7(5), 651-667.

Tananuraksakul, N. (2012). Non-native English students' linguistic and cultural challenges in Australia. Journal of International Students, 2(1), 107-115.

Watanabe, Y. (2008). Peer-peer interaction between L2 learners of different proficiency levels: Their interactions and reflections. The Canadian Modern Language Review, 64(4), 605-635.

Watanabe, Y., \& Swain, M. (2007). Effects of proficiency differences and patterns of pair interaction on second language learning: Collaborative dialogue between adult ESL learners. Language Teaching Research, 11(2), 121-142. doi:10.1177/136216880607074599

Teresa Chen, $\mathrm{PhD}$, serves as Associate Professor in the Department of Advanced Studies in Education and Counseling at California State University, Long Beach. Her research interests include academic literacies and computer-assisted language learning. Email: Teresa.Chen@csulb.edu

Manuscript submitted: August 31, 2016

Manuscript revised: April 22, 2017 Accepted for publication: October 10, 2017 